\title{
CONSTRUCTION OF A LOW COST AIR SAMPLER AND IT'S APPLICATION IN SAMPLING VOLATILE CARBONYL COMPOUNDS
}

\author{
K I A Kularatne and K R Ranjith Mahanama \\ University of Colombo.
}

Interest is expanding in measuring. concentrations of volatile organic compounds in buildings since it is recognised that many peoples exposure 10 these compounds occur in the indoor environment. However, such data are not available in Sri Lanka primarily due 10 lack of proper equipment for quantitation and their high maintenance cost. This paper describes the construction of a low cost air sampler (Rs. 400/=) using commonly available materials.

The air sampler contains a muffer fan to pull ambient air though a filter(s) and/or a bed of sorben material, which are housed in a variable length PVC tube. Battery powered mufler fan and lightweight are two of the convenient features of this air sampler that minimise operational and transportation difficulties to the user.

Volatite carbonyl compounds such as formaldehyde acetaldehyde and acetone are commonly found in indoors ambient air due to the combustion sources and emissions from svnthetic houschold products. Since formaldehyde is a known carcinogen and acetaldehyde is a suspected carcinogen compound, they were selected as the model compounds for the evaluation of constructed sampler. A filter paper spiked with 2, 4 dinitrophenylhydrazene is used to collect the airborne carbonyl compounds at a flow rate of $1.8 \mathrm{~cm}^{3} / \mathrm{sec}$. Filters were sonicated in methanol and extracts were separated using a $\mathrm{C}_{1 \times}$ column for quantitation at $350 \mathrm{~mm}$ wavelength. Quantitation limits estimates that sampling of $10 \mathrm{dm}^{3}$ ambient air enables minimum quantitation of 0.5 formaldehyde, 1.0 acetaldehyde and 1.2 acetone accurately. The paper also reports quantified levels of airbone carbonyls from different indoor environments.

Preceedings of the Fenth Annual Forestry and Environment Symposium 1998 of the Department of Forestry and Envirommental Science, University of Sri Jayewardenepura, Sri Lanka 